\title{
A comunicação de informações nas instituições públicas e privadas: o caso XBRL - eXtensible Business Reporting Language no Brasil*
}

\author{
Orandi Moreira** \\ EDSON LUIZ RICCIO*** \\ Marici Cristine Gramacho Sakata****
}

SuMÁRIo: 1. Introdução; 2. Metodologia da pesquisa; 3. Resultados; 4. Considerações finais.

SUMmary: 1. Introduction; 2. Research method; 3. Results; 4. Final remarks.

PALAVRAS-CHAVE: XBRL; relatório financeiro; difusão de conhecimento; governança corporativa; internet.

KEY WORDS: XBRL; financial statements; knowledge diffusion; corporate governance; internet.

O XBRL - eXtensible Business Report Language - é uma linguagem que está sendo implementada em vários países para divulgação das informações contábil-financeiras pela internet. Este artigo mostra o estado-da-arte do XBRL e como se deu sua evolução, bem como avalia o estágio atual do

\footnotetext{
* Artigo recebido em out. 2005 e aceito em dez. 2006.

** Fiscal de rendas da Secretaria da Fazenda de São Paulo e pesquisador do Laboratório de Tecnologia e Sistemas de Informação da Faculdade de Economia e Administração da Universidade de São Paulo (Tecsi FEA/USP). Mestre em contabilidade e controladoria pela FEA/USP. Endereço: Av. Prof. Luciano Gualberto, 908 - FEA 3 - CEP 05508-900, São Paulo, SP, Brasil. E-mail: orandi@usp.br.

*** Professor livre-docente do Departamento de Contabilidade da FEA/USP, presidente da Comissão de Cooperação Internacional (CCInt FEA). Doutor em administração pela FEA/USP. Endereço: Av. Prof. Luciano Gualberto, 908 - FEA 3 - CEP 05508-900, São Paulo, SP, Brasil. E-mail: elriccio@usp.br.

***: Pesquisadora do Tecsi FEA/USP. Doutoranda em ciências da comunicação pela ECA/USP. Endereço: Av. Prof. Luciano Gualberto, 908 - FEA 3 - CEP 05508-900, São Paulo, SP, Brasil. E-mail: mcsakata@usp.br.
} 
Brasil na divulgação de informações contábil-financeiras pela internet. Foi realizada uma pesquisa do tipo survey com empresas de capital aberto no Brasil. A pesquisa revelou uma forte aceitação do meio eletrônico para divulgação de informações financeiras e também que ainda é muito pequeno o conhecimento da linguagem XBRL no país e, conseqüentemente, menor ainda o número de entidades que já iniciaram formalmente os estudos para sua implementação. Mostrou ainda a inexistência de um padrão de divulgação de informações eletrônicas, tendo predominado os formatos PDF, HTML e DOC, o que dificulta a análise e comparação de informações entre órgãos reguladores e com o público em geral.

The communication of information in public and private institutions: the case of XBRL - eXtensible Business Reporting Language in Brazil $\mathrm{XBRL}$ - eXtensible Business Report Language - is a language for the dissemination of financial information on the internet and is being implemented in different countries. The major purpose of this research was to show XBRL state-of-the-art and its evolution, as well as to assess the current status of financial information dissemination on the internet in Brazil. Additionally, a survey with open capital companies in Brazil so as to detect the dissemination of financial statements on the internet was also carried out, focusing on the future expansion of XBRL use in the business environment. The research revealed a strong acceptance of the electronic media for dissemination of financial information, but that there is still very little knowledge of XBRL and that the number of institutions already studying the implementation of the language in the country is even smaller. It also showed the inexistence of a pattern of dissemination of electronic information; the prevailing formats were PDF, HTML and DOC, which hinders data analysis and comparison by regulatory agencies and by the general public.

\section{Introdução}

Os termos globalização e nova economia permeiam nosso dia-a-dia e têm afetado a sociedade como um todo. Os acontecimentos em um lado do mundo, por reações em cadeia, afetam as economias do outro lado. Assim, "a globalização influi tanto em nossa vida diária como nos acontecimentos que ocorrem em escala mundial" (Giddens, 2000:16). Tal influência é possibilitada e impulsionada pelos meios de comunicação e pela tecnologia, seja em uma relação de colaboração, seja em uma relação de dependência. A globalização também é responsável pela padronização dos processos de gestão e controle empresarial. Determinados padrões de atuação e de infra-estrutura tecnológica 
são replicados nas diversas localidades. Um exemplo de padronização de processos e infra-estrutura de informações administrativo-financeiras com uso de tecnologia são os sistemas empresariais integrados ou Enterprise Resource Planning (ERP) (Riccio, 2001:30).

Em todos os países, organizações públicas e privadas necessitam implementar procedimentos de governança corporativa, prestar conta de suas atividades e divulgar suas informações, entre elas as de natureza contábilfinanceira. No Brasil, como em outros países, a divulgação das demonstrações contábil-financeiras das empresas de capital aberto deve seguir as determinações da Lei no 6.404/76 (Lei das Sociedades Anônimas) e as normas da Comissão de Valores Mobiliários (CVM). Na área pública, a Constituição brasileira de 1988 instituiu entre seus princípios o da publicidade das informações.

Para Bulos (2000), o princípio da publicidade tem como escopo manter a total transparência na prática dos atos da administração pública. O art. 48 da Lei de Responsabilidade Fiscal (LC no 101/2000) estabelece que deve ser dada ampla divulgação da gestão fiscal, inclusive em meios eletrônicos de acesso público. A Lei nº 9.755/98 determina que toda entidade gestora de recursos públicos deve divulgar suas movimentações financeiras no portal da internet Contas Públicas, que é mantido pelo Tribunal de Contas da União (TCU), enquadrando nessa obrigatoriedade todas as entidades públicas das esferas federal, estadual e municipal, das administrações públicas diretas, indiretas e fundacionais dos poderes Legislativo, Executivo e Judiciário. Nesses casos, a preocupação com a transparência é que predomina, tanto na área privada quanto na área pública. No entanto, no ambiente globalizado, as informações precisam ter a mesma dinâmica com que fluem as informações do mercado financeiro, e também precisam ser confiáveis para que possam ser utilizadas pelos destinatários, além de permitirem a comparabilidade entre as informações das diversas entidades. A internet, pelo alcance mundial, tornou-se um elemento causador de profunda mudança na forma como as pessoas e as organizações se comunicam. Pelas suas características e baixo custo, pode ser utilizada em sua potencialidade máxima por qualquer porte de instituição e pelo público.

Da junção de tecnologias já existentes surgiu o XBRL - eXtensible Business Report Language, uma nova linguagem tecnológica para o cenário econômico-financeiro voltado à divulgação de relatórios com informações padronizadas. O XBRL foi concebido a partir da linguagem XML - eXtensive Markup Language, que otimiza a transmissão de informações pela internet. Com o uso crescente no cenário mundial e a sua influência no mundo financeiro, faz-se necessário compreender seu histórico e o seu estado-da-arte.

É importante que o Brasil faça parte desse círculo de desenvolvimento, uma vez que a maioria das instituições está inserida no mercado financeiro 
mundial. Assim, as entidades fiscalizadoras governamentais como Banco Central, Receita Federal e receitas estaduais, Comissão de Valores Mobiliários, entre outras, necessitam solicitar formalmente às entidades que disponibilizem suas informações em um formato-padrão. Isso proporcionaria uma maior facilidade na coleta e agregação dos dados no menor tempo possível, possibilitanto uma análise e comparatividade em nível econômico e financeiro nos segmentos de mercados envolvidos e, conseqüentemente, maior confiabilidade no processo.

\section{Objetivo}

Este artigo estuda a proposta da linguagem XBRL, seu estágio de utilização em outros países, e como o Brasil pode utilizá-la. Também detecta se esse é o caminho a ser seguido pelas empresas públicas e privadas que almejam utilizar a internet como meio de divulgação de informações, em substituição ou complemento, aos formatos atualmente utilizados.

Este artigo está estruturado em quatro partes: apresentar o histórico do XBRL; entender a fonte da linguagem, origem, forma de apresentação; detectar seus principais pólos de desenvolvimento, grupos de pesquisa, instituições e eventos e conhecer como os governos e as entidades reguladoras do mercado financeiro dos diversos países estão se envolvendo em sua implementação, e conhecer como a divulgação das informações contábil-financeiras estão sendo feitas pelas empresas de capital aberto no Brasil, e o atual grau de conhecimento da XBRL nas instituições pesquisadas.

\section{Histórico do XBRL}

As linguagens de marcação (XML — Markup Language) tiveram sua origem em 1960, quando a IBM constatou que diferentes tipos de sistemas não "conversavam" entre si, ou seja, não eram integrados. A solução dada por sua engenharia foi então a primeira linguagem de marcação, denominada GML Generalized Markup Language. A linguagem de marcação é considerada uma metalinguagem, cujo propósito é descrever um método para descrição de dados, estabelecendo uma série de regras e procedimentos que permitam identificar como funciona um conjunto de informações, sendo assim um protocolo de normas (Aliana, 2004:4). O nome markup significa as marcas, ou labels, que identificam onde e como a informação deverá aparecer. Assim, é uma metalinguagem que permite construir uma linguagem. Em 1990, o físico suíço Tim Berners-Lee liderou o desenvolvimento da linguagem de marcação HTML, 
Hypertext Markup Language, e denominou tal sistema de WWW, World Wide Web, que foi parcialmente responsável pela explosão da internet (Hoffman e Strand, 2001:35).

O hipertexto é um documento capaz de incluir em seu conteúdo ligações com outras partes do mesmo documento ou com documentos diferentes. A linguagem HTML aparentemente veio resolver o problema de complexidade, pois sua simplicidade e praticidade foram alguns dos fatores responsáveis pela "explosão" da internet. Porém, tal simplicidade também foi fator de limitações. Por ser muito estática e permitir apenas que se apresentasse informação, não possibilitava outras formas de interação. A solução veio em 1998, quando o consórcio internacional World Wide Web Consortium (W3C) desenvolveu tecnologias para a web e disponibilizou formalmente a linguagem XML, que é compatível com a linguagem SGML - Standard Generalized Markup Language, mas considerada menos complexa, podendo incorporar códigos de formatação com uma grande variedade de programas de computador.

\section{A linguagem $X B R L$}

A história do XBRL teve início em abril de 1998, quando Charles Hoffman, Certified Public Accountant (CPA), de Washington, passou a pesquisar o uso da linguagem XML para passar informações financeiras para divulgação eletrônica (Truman State University, 2004). Em 1998 apresentou suas idéias ao American Institute of Certified Public Accountants (AICPA), que se interessou e apoiou seu projeto. Em janeiro de 1999 surgiu o protótipo do projeto. Convencido da utilidade da linguagem, o AICPA deu início a um projeto, em junho de 1999, denominado XFRML - eXtensible Financial Reporting Markup Language. Em agosto de 1999, mais 11 companhias também se juntaram ao projeto e formaram o comitê de desenvolvimento da linguagem, entre elas: Arthur Andersen, Ernest \& Young, Edgar Online, KPMG, Microsoft Corporation, PricewaterhouseCoopers. O nome do consórcio foi mudado oficialmente, em abril de 2000, para XBRL e, em julho de 2000, foi anunciada a conclusão da taxonomia para companhias comerciais e industriais dos EUA, sendo também anunciada a internacionalização do consórcio, visando rápida expansão da linguagem (XBRL History, 2004). Os termos HTML, XML e XBRL estão fortemente relacionados, porém necessita-se fazer a distinção clara entre cada um deles.

O HTML é um sistema de marcação de documento específico para publicação na rede mundial www. Os documentos HTML contêm referências gráficas e rótulos (tag) que descrevem como o documento aparecerá na internet, 
mostrando, por exemplo, qual a fonte, cor, tamanho e outras características necessárias quando se envia um texto para a tela. Porém, contém apenas dados brutos e não informações, uma vez que tudo deve ser informado para que seja publicado. O XML por sua vez também utiliza rótulos tag, porém não delimita um número predefinido de tags. Também permite uma rede de referências predefinida (taxonomia) e as devidas relações entre elas.

A linguagem XML é mantida pelo consórcio W3C, na qual os dados são independentes e podem ser encaminhados a qualquer dispositivo, como computador, telefone celular, e outros, e permite a seus desenvolvedores oferecerem os dados de maneira uniforme e consistente. O XBRL, por sua vez, é baseado na linguagem XML, tendo sido desenvolvido especificamente para a emissão de relatórios financeiros, e, sendo assim, pode ser considerado um complemento adicional ao XML.

\section{Relatórios financeiros usando XBRL}

Relatórios financeiros são um conjunto de resumos de informações referentes a recursos e obrigações de uma entidade, emitidos em intervalos regulares. As empresas fornecem informações para credores, investidores, analistas, entidades reguladoras, governo, associações e público, entre outros. Para Farewell (2004:2), cada um desses grupos requer as informações em um formato específico e, com isso, as empresas extraem informações de seus sistemas e as transcrevem nos formatos requeridos por cada grupo de usuários que, por sua vez, transcrevem essas informações em seus sistemas. O XBRL elimina a necessidade de transcrição de dados entre as aplicações, porque o dado passa a ser independente do aplicativo no qual ele é criado (os dados são mantidos de forma independente e sob uma denominação preestabelecida e padronizada). Essa definição faz com que múltiplos usuários sejam capazes de extrair e reposicionar as informações financeiras. Assim, o próprio usuário recupera as informações financeiras pela internet e passa para o formato que desejar, de acordo com suas necessidades de análise.

Na esfera governamental, a Lei no 9.755/98 determina que todas as entidades gestoras de recursos públicos disponibilizem na internet, no site do TCU, informações detalhadas sobre tributos arrecadados, recursos repassados, transferências constitucionais, orçamentos anuais, execução de orçamentos, balanços orçamentários, demonstrativos de receitas e despesas, contratos e seus aditivos e compras. Se forem somadas as informações a serem disponibilizadas pela União, com as dos 27 estados e o Distrito Federal e com os 5.560 
municípios do país (segundo o IBGE em 2005), tem-se uma grande quantidade de informações públicas que precisam circular pela internet, sendo que até o presente momento não houve padronização na forma como elas devem ser apresentadas, o que dificulta a sua coleta e análise. Assim, faz-se necessário buscar alternativas de coleta, troca e divulgação de informações entre os entes públicos, que atendam a essa dinâmica e possibilitem intercâmbio rápido e seguro de dados.

A utilização do XBRL facilita o agrupamento e análise de informações, bem como a sua comparação. Também beneficia a preparação de relatórios e sua análise. Sua utilização diminui os custos de preparação de relatórios e a freqüência de erros, uma vez que elimina a necessidade de redigitação de dados, de um formato de relatório para outro. Para Silva (2003:26), “o XBRL oferece vários benefícios, como independência de tecnologia, interoperabilidade, preparação eficiente de relatórios financeiros e facilidade de extração dos dados".

Várias outras vantagens podem ser obtidas com a utilização da linguagem. Se todos passarem a utilizá-la, ter-se-á uma padronização, que facilitará o intercâmbio de informações entre as entidades e reduzirá a necessidade de conversão freqüente de arquivos que ocorre atualmente. Também haverá maior divulgação das informações, uma vez que a facilidade, propiciada com o uso da internet, possibilitará acesso a um número significativamente maior de usuários interessados nessas informações. Para Queiroz (2004:1) “o tratamento digital da informação traz como conseqüência a desmaterialização do documento, que deixa de ser representado no suporte clássico de papel, passando a ser representado em meio magnético, libertando os documentos do formato que tiveram durante séculos".

Como os dados são informados apenas uma vez e por uma única fonte, deixaria de haver redundância no fornecimento e coleta das informações e, conseqüentemente, eliminar-se-iam os constantes erros causados nos processos de redigitação, reduzindo também os custos. E, com a padronização no fornecimento das informações, softwares especializados podem ser desenvolvidos, visando depurar e avaliar os dados de maneira automatizada, reduzindo significativamente o tempo de coleta e integração e aumentando a confiança no processo de depuração.

No entanto, algumas considerações precisam ser levantadas na avaliação da linguagem. A primeira dificuldade, como é comum em implementações de novas tecnologias em um país são os custos para criação de grupos que possam desenvolver $\mathrm{a}(\mathrm{s})$ taxonomia(s) necessária(s) a cada área de atuação. A solução, ou pelo menos para minimizar esses custos, será a união das entida- 
des regulatórias nacionais, para que se canalizem recursos voltados para cada área, concentrando esforços e evitando duplicação de estudos e conseqüentemente de custos.

A fim de garantir a autenticidade e a confiabilidade das informações transmitidas pela internet em geral, alguns setores específicos do governo brasileiro já começaram a trabalhar em medidas visando dar os primeiros passos no sentido de se implantar a chamada certificação digital das informações.

\section{Metodologia da pesquisa}

Para que se possa saber o grau de desenvolvimento em um país, é necessário buscar meios de quantificar a utilização ou o envolvimento com o objeto em estudo. O desenvolvimento da ciência e tecnologia é hoje um instrumentochave no âmbito político, dado o impacto nos processos econômicos dos países. Como conseqüência dessa importância na economia, uma variedade de indicadores para mensurar e mapear as atividades tecnológicas e científicas tem sido desenvolvida nas últimas décadas (Veerbeek et al., 2002:179). A bibliometria fornece alguns indicadores e ferramentas para mensurar esse desenvolvimento. A unidade principal de mensuração na bibliometria é composta pelas publicações científicas, que incluem relatórios de pesquisa, livros, anais de conferências e artigos em revistas científicas, entre outros.

Para cumprir com os objetivos desta pesquisa, na primeira etapa, a técnica utilizada foi a revisão bibliográfica e documental. Os resultados obtidos permitiram que dados qualitativos fossem levantados gerando bases para uma posterior análise das mudanças. As questões de pesquisa da análise bibliométrica que serviram de base para esta pesquisa foram:

จ quais os países e organizações que estão mais ativos em uma específica (sub) área de estudo?

จ quais as mudanças de padrão que vêm ocorrendo ao longo do tempo?

v qual o impacto (influência real nas atividades de pesquisa em um dado tempo) de um grupo ou instituição de pesquisa?

จ quais organizações estão envolvidas nas mudanças cruciais na (sub) área específica de estudo?

O segundo passo foi o survey Rea e Parker (2000) em nível nacional, que buscou conhecer o posicionamento de empresas de capital aberto, públicas e privadas, quanto ao estágio atual e intenção futura de divulgação de suas 
demonstrações financeiras pela internet. Na pesquisa empírica fez-se um levantamento junto a empresas de capital aberto nacionais públicas e privadas, procurando saber como está sendo vista a opção de divulgar as movimentações financeiras, utilizando a internet.

\section{Universo da pesquisa e amostra}

A amostra abrangeu as empresas de capital aberto, públicas e privadas nacionais, constituídas sob a forma de sociedade por ações, que periodicamente necessitam apurar suas demonstrações financeiras e, de acordo com a Lei $\mathrm{n}$ o 6.404/76, disponibilizá-las a seus usuários e investidores.

Os questionários foram enviados, pela internet, para os responsáveis pela área de relações com investidores (RI) de 605 empresas de capital aberto nacionais listadas na Bovespa. O volume efetivo de respostas foi de 132. Foram formuladas cinco questões fechadas, quatro delas com alternativas "Sim", "Não" ou "Desconhece" e uma alternativa para resposta numérica, correspondendo a um intervalo de tempo, além de um espaço de cinco linhas, para comentários adicionais.

\section{Resultados}

São apresentados, separadamente, os resultados da pesquisa bibliográfica em nível mundial e da pesquisa empírica nacional.

\section{O XBRL internacional}

O XBRL é um software livre e aberto desenvolvido pela entidade XBRL International com sede nos EUA. Em dezembro de 2003 foi lançada a versão XBRL 2.1 Specification. Atualmente, cerca de 250 companhias do mundo, associações e agências governamentais estão trabalhando juntas no desenvolvimento do software uma vez que muitos países estão observando progresso significativo na adoção da linguagem (XBRL International, 2004).

Para o desenvolvimento da linguagem em todo o mundo, o Consórcio Internacional XBRL mantém jurisdições em vários países do mundo. Elas são consórcios locais de entidades públicas, privadas e órgãos reguladores, unidos com o objetivo comum de dedicar estudos, desenvolver e incentivar o desenvolvimento e manutenção das taxonomias para adoção do XBRL específico do país. Podem representar um país, uma região ou um regime internacionalmen- 
te reconhecido de regulação de normas contábeis ou financeiras. Embora o XBRL seja um software livre, a linguagem (taxonomia) deve estar de acordo com as normas de cada país, e, portanto, são necessários grupos onde estejam envolvidas entidades governamentais e privadas que determinem a taxonomia XBRL de seu país.

Atualmente 10 países do mundo já estabeleceram jurisdição e quatro estão com jurisdições ainda provisórias. Outros países ainda não formalizaram sua jurisdição, porém já tiveram seus processos iniciados, como Áustria, China, Eslovênia, França, Grécia, Hungria, Itália, Luxemburgo, Noruega, Portugal, República Tcheca, Cingapura, Brasil e Suíça.

Em todos os países, sem exceção, a sede das jurisdições, que é a liderança do grupo, fica a cargo de instituições governamentais ou reguladoras, e não em instituições privadas como se observa no quadro.

\begin{tabular}{|ll|}
\hline & Jurisdições estabelecidas e provisórias \\
\hline Países & Sedes de jurisdições estabelecidas \\
\hline EUA & AICPA \\
Alemanha & Deutsche Börse AG e Deutsche Vereinigung für Finanzanalyse and Asset Management \\
& (DVFA GmbH) \\
Austrália & Institute of Chartered Accountants in Australia (ICAA) e Certified Public Accountant \\
& of Australia (CPA Australia), com assistência financeira do Australian Governments \\
& National Office for the Information Economy \\
Canadá & Canadian Institute of Chartered Accountants \\
Espanha & Banco de España e Asociación Española Contab. Admin. de Empresas \\
Holanda & Koninklijk Nederlands Institute van Registeraccountants (NIVRA) e Samenwerkende \\
Inglaterra & Registeraccountants en Accountants-Administratieconsulenten (SRA) \\
Irlanda & Institute of Chartered Accountants in England \& Wales (ICAEW) \\
Japão & Institute of Chartered Accountants in Ireland, Central Statistics Office, Companies \\
Nova Zelândia & Registration Office e a Revenue Commissioners \\
Bélgica & Japanese Institute of Certified Public Accountants (JICPA) \\
Coréia do Sul & Institute of Chartered Accountants of NZ \\
Dinamarca & National Bank of Belgium \\
Suécia & Korea Association for CFOs \\
\hline Fonte: XBRL International. & Foreningen af Statsautoriserede Revisorer (FSR) \\
& Foreningen for revisionsbyrabranschen (FAR) \\
\hline
\end{tabular}




\section{Eventos de divulgação do XBRL promovidos no mundo}

O XBRL International e a IASC Foundation, desde o ano de 2001, promovem duas vezes por ano uma conferência internacional de XBRL, na qual expositores de todo o mundo podem mostrar suas idéias e progressos obtidos no desenvolvimento da linguagem. O Bryant College, em Rhode Island, EUA, um centro de pesquisas na tecnologia XBRL, realiza anualmente a XBRL Conference at Bryant College, que trata dos temas: taxonomia, desenvolvimento de aplicações e pesquisas em XBRL; e realiza competição acadêmica aplicada, de trabalhos desenvolvidos sobre esse tema.

\section{Resultados da pesquisa empírica}

Dos 605 questionários enviados, 132 foram devidamente respondidos. A descrição e análise de cada questão são apresentadas a seguir.

Na questão 1 foi perguntado se a empresa disponibiliza as demonstrações financeiras pela internet. Nessa questão 92 empresas responderam "Sim" $(69,7 \%)$ e 40 responderam "Não" (30,3\%). Tem-se então uma alta percentagem de empresas que divulgam as informações financeiras pela internet, o que evidencia a aceitação desse meio de divulgação.

Na questão 2, caso a empresa não publicasse as demonstrações financeiras pela internet, foi perguntado se existe a intenção de futuramente fazê-lo. Essa questão deveria ser respondida exclusivamente por aquelas que responderam "Não" na questão anterior. Obteve-se um total de 14 "Sim", constatando-se que mesmo entre aquelas que ainda não divulgam pela internet, 35\%, têm intenção de vir a publicar nesse meio, o que levou a uma extrapolação, considerando aqueles que já publicam e os que pretendem futuramente realizálo. Ou seja, somando-se os que já divulgam pela internet (92) com os que têm intenção declarada de fazê-lo no futuro (14), obtém-se o potencial efetivo de utilização da internet da amostra, que é 106 , ou seja, $80,3 \%$ das 132 , o que representa mais de $2 / 3$ do total de empresas, enfatizando ainda mais a importância desse meio para disponibilizar informações financeiras.

$\mathrm{Na}$ questão 3, foi perguntado se o respondente conhece a linguagem XBRL, específica para publicação de informações financeiras pela internet. Apenas 10 empresas responderam "Sim" a essa questão, constatando-se que uma parcela muito pequena delas $(7,6 \%)$ já tem algum conhecimento da linguagem XBRL. Os autores consideram de fundamental importância a divulgação de informações sobre o tema com materiais impressos e promoção de workshops e seminários abertos ao público em geral. 
Na questão 4 foi perguntado se a empresa possui uma pessoa ou grupo de pessoas responsáveis pelo estudo da implementação do XBRL em sua empresa. Também nessa questão apenas três empresas responderam "Sim", constatando-se que é ainda menor (2,3\%) a proporção de empresas que já possuem pessoas estudando a implementação da linguagem.

Na questão 5 foi perguntado se caso a empresa tivesse intenção de publicar na internet, utilizando o XBRL, qual o prazo previsto para iniciar a publicação nessa modalidade.

Apenas duas empresas responderam que "Sim", ou seja, 1,5\% delas, já definiram prazos para início das divulgações no formato XBRL.

\section{Análise dos formatos das demonstrações apresentadas atualmente na internet}

Dando continuidade à pesquisa, foram selecionadas as 92 empresas que responderam "Sim" à "questão 1" e acessadas na internet suas informações, buscando-se assim conhecer as formas atualmente mais utilizadas para apresentação dessas informações. O resultado é apresentado na tabela.

\begin{tabular}{|lcc|}
\hline \multicolumn{3}{|c|}{$\begin{array}{c}\text { Formatos de divulgação das } \\
\text { demonstrações financeiras }\end{array}$} \\
\hline Formato & № de empresas & $\%$ \\
\hline PDF & 39 & 42,4 \\
HTML & 25 & 27,2 \\
DOC & 24 & 26,1 \\
XLS & 4 & 4,3 \\
Total & 92 & 100 \\
\hline
\end{tabular}

O resultado obtido revelou não existir na amostra padronização na forma de apresentação das informações. Os formatos mais encontrados foram o PDF, o HTML e também a apresentação em Word, e, em menor quantidade, apresentações utilizando arquivos do Excel.

\section{Considerações finais}

Entre os países mais ativos no desenvolvimento do XBRL pode-se afirmar que estão os EUA, Alemanha e Japão. Nos EUA começaram os estudos e onde se encontra a sede do consórcio internacional que concentra os estudos da lin- 
guagem. A Alemanha está em estágio avançado no desenvolvimento de taxonomias e o Japão é o país que tem o maior número de entidades apoiando o projeto. Canadá, Austrália, Espanha e Coréia do Sul, apesar de estarem estudando a linguagem há menos tempo, revelam-se fortemente empenhados em sua implementação.

Com a adoção mundial do XBRL, os diversos padrões de divulgação das informações financeiras são unificados em um formato, de acordo com a taxonomia adotada. Em diversos países, grupos compostos por acadêmicos, membros de órgãos governamentais e desenvolvedores de softwares estão sendo formados, a fim de se estudarem fórmulas de adaptação às necessidades geradas pela nova forma de apresentação de informações financeiras.

O XBRL não é mais um fenômeno local dos EUA, ou específico de uma entidade, mas já está presente formalmente em pelo menos 14 países considerados entre os mais adiantados do mundo, tendo ainda outros países já iniciado o processo de montagem da jurisdição. Apesar de ainda não haver uma jurisdição formal no Brasil, Argentina, Portugal, Colômbia, Venezuela e outros, já despontam estudos acadêmicos, e há interesse de entidades públicas, privadas ou regulatórias em estabelecerem uma jurisdição.

Quanto às organizações envolvidas nas mudanças específicas do XBRL, percebe-se a criação em vários países de representantes locais do XBRL International, estando alguns já estabelecidos e outros iniciando esse processo. Em todos esses países percebe-se a forte presença de setores governamentais, associações e conselhos de classe, comissões de representantes de empresas de capital aberto, autoridades tributárias e órgãos reguladores de instituições financeiras, os quais têm mais facilidade de levar o processo adiante.

A pesquisa empírica nacional revelou uma intensa aceitação do meio eletrônico para divulgação de informações financeiras, e também que ainda é muito pequeno o conhecimento da linguagem XBRL no país e conseqüentemente menor ainda o número de entidades que já iniciaram formalmente os estudos para implementação da linguagem.

Mostrou também a inexistência de um padrão de divulgação de informações eletrônicas, tendo predominado os formatos PDF, HTML e DOC, o que dificulta o intercâmbio de informações entre os usuários.

\section{A difusão do XBRL no Brasil}

No Brasil, o Laboratório de Tecnologia e Sistemas de Informação da Unversidade de São Paulo (Tecsi) desde 2004 tem realizado pesquisas e promovido eventos como o Congresso Internacional de Gestão de Tecnologia e Sistemas de In- 
formação (Contecsi) e o Workshop Brasileiro de XBRL para o estudo e divulgação do XBRL no Brasil. O primeiro workshop brasileiro de XBRL (setembro de 2004) contou com representantes e membros de instituições governamentais e representativas de classe como o Banco Central do Brasil, Comissão de Valores Mobiliários, Bovespa, Fundação Brasileira de Contabilidade, Conselho Federal de Contabilidade, Instituto dos Auditores Independentes do Brasil (Ibracon), Associação Nacional de Investidores do Mercado de Capitais, Sindicato dos Contabilistas de São Paulo, além de cerca de 40 instituições privadas (Tecsi, 2004; Riccio, 2004). Quanto à implementação na área governamental, Silva (2003) identificou no Banco Central do Brasil três ambientes de informações financeiras que podem ser comuns a qualquer órgão, identificou os benefícios que o XBRL poderia trazer ao setor público, propôs o desenvolvimento de taxonomias para suas próprias demonstrações financeiras e para aquelas que são repassadas pelas entidades financeiras e já desenvolveu uma proposta de taxonomia para representação dos balanços patrimoniais do Banco Central, utilizando XBRL. O caminho para a implantação do XBRL no Brasil acompanha os seguidos pelos demais países que já iniciaram esse processo, qual seja, formar um grupo de pesquisas, sediado por uma entidade governamental ou reguladora do mercado financeiro ou contábil e concentrar esforços na criação das taxonomias brasileiras para os diversos tipos de setor de atividade.

\section{O futuro do XBRL no Brasil}

O Brasil todo poderá obter benefícios quando as entidades governamentais estiverem utilizando o potencial de acesso e disponibilização das informações financeiras, devido à padronização do fluxo de informações, eliminação da redundância, acesso de formas diferentes pelos vários sistemas, facilidade no grupamento e análise das informações, bem como a comparabilidade entre as informações de entidades diferentes, redução de erros e custos, possibilidade de comunicação entre softwares diferentes e aumento substancial da facilidade de extração das informações.

Para o governo, que atua como fiscalizador e regulador do mercado financeiro, o XBRL pode se tornar um importante instrumento, pois a padronização no fluxo de informações pode facilitar e auxiliar o seu tratamento e análise, possibilitando a implementação de processos de governança e de transparência na gestão pública. A XBRL facilitará o atendimento à Lei no 9.755/98 na divulgação das informações públicas referentes à movimentação financeira da União, estados, Distrito Federal e municípios. 


\section{Referências bibliográficas}

ALIANA, T. XBRL: el reporting financiero sobre internet. Disponível em: <www.asset.es/ miembros/articulo_antoni_aliena.doc>. Acesso em: 23 nov. 2004.

BRASIL. Lei n. 6.404 de 15 de dezembro de 1976. Dispõe sobre as sociedades por ações. Brasília, 1976.

. Constituição da República Federativa do Brasil. Brasília, DF, 1988.

. Lei n. 9.755 de 16 de dezembro de 1998. Dispõe sobre a criação de homepage, pelo Tribunal de Contas da União. Brasília, DF, 1998.

. Lei Complementar n. 101 de 4 de maio de 2000. Estabelece normas de finanças públicas voltadas para a responsabilidade na gestão fiscal e dá outras providências. Brasília, DF, 2000.

BULOS, U. L. Constituição Federal anotada. São Paulo: Saraiva, 2000.

FAREWELL, S. A plan for implementing XBRL in an introductory AIS course. In: AAA-IS SECTION MID-YEAR CONFERENCE. University of Arkansas at Little Rock, 2004.

GIDDENS, A. Un mundo desbocado: los efectos de la globalización en nuestras vidas. Madrid: Santillana, 2000.

HOFFMAN, C.; STRAND, C. XBRL essentials. New York: AICPA, 2001.

QUEIROZ, R. M. Comércio eletrônico e a certificação digital: segurança possível. 2004. Disponível em: <www.consciência.br/reportagens/internet/net07.htm/> . Acesso em: 14 fev. 2005.

REA, L. M.; PARKER, R. A. Metodologia de pesquisa: do planejamento à execução. São Paulo: Pioneira, 2000.

RICCIO, E. L. Efeitos da tecnologia de informação na contabilidade: estudo de casos de implementação de sistemas empresariais integrados — ERP. 2001. Tese (Livre-Docência) - Programa de Pós-Graduação em Administração, Departamento de Administração, Faculdade de Economia, Administração e Contabilidade da Universidade de São Paulo, São Paulo.

. Relatório sobre o 1o Workshop Brasileiro de XBRL — Tecsi/FEA/USP. Disponível em: <www.tecsi.fea.usp.br/eventos/workshopxbrl01>. Acesso em: 31 jul. 2004.

SILVA, P. C. da. Explorando linguagens de marcação para representação de relatórios de informações financeiras. 2003. Dissertação (Mestrado Profissional em Redes de Computadores) - Programa de Pós-Graduação em Redes de Computadores da Universidade Salvador, Salvador. 
. A gestão eletrônica da informação financeira apoiada por XBRL. In: CONGRESSO DE INFORMÁTICA PÚBLICA, 10., São Paulo, 2004.

TECSI (LABORATÓRIO DE TECNOLOGIA E SISTEMAS DE INFORMAÇÃO) In: CONTECSI, CONGRESSO INTERNACIONAL DE GESTÃO DE TECNOLOGIA E SISTEMAS DE INFORMAÇÃO, 1. Anais... Disponível em: <www.tecsi.fea.usp.br/eventos/contecsi2004>. Acesso em: 31 jul. 2004.

TRUMAN STATE UNIVERSITY. A presentation on XBRL. Disponível em: <www2.truman.edu/ a1690/xbrl2.htm>. Acesso em: 23 nov. 2004.

VEERBEEK, A. et al. Measuring progress and evolution in science and technology - I: the multiple uses of bibliometric indicators. International Journal of Management Reviews, Malden, v. 4, n. 2, p. 179-211, June 2002.

XBRL HISTORY. 2004. Disponível em: <www.xbrl.org/history-print.aspx> . Acesso em: 23 nov. 2004.

XBRL INTERNATIONAL. Progress report. 2004. Disponível em: <www.xbrl.org>. Acesso em: 23 nov. 2004. 